\title{
Assessing the effects of the percentage of chronic disease in households on health payment-induced poverty in Shaanxi Province, China
}

Xin Lan ${ }^{1} \mathbb{B}$, Zhongliang Zhou ${ }^{2 *}$, Yafei $\mathrm{Si}^{2}$, Chi Shen ${ }^{2}$, Xiaojing Fan ${ }^{1}$, Gang Chen ${ }^{3}$, Dantong Zhao ${ }^{1}$ and Xi Chen ${ }^{4}$

\begin{abstract}
Background: Chronic disease has become one of the leading causes of poverty in China, which posed heavy economic burden on individuals, households and society, and accounts for an estimated $80 \%$ of deaths and $70 \%$ of disability-adjusted life-years lost now in China. This study aims to assess the effect of chronic diseases on health payment-induced poverty in Shaanxi Province, China.

Methods: The data was from the 5th National Health Survey of Shaanxi Province, which was part of China's National Health Service Survey (NHSS) conducted in 2013. Totally, 20,700 households were selected for analysis. We used poverty headcount, poverty gap and mean positive poverty gap to assess the incidence, depth and intensity of poverty before and after health payment, respectively. Logistic regression models were further undertaken to evaluate the influence of percentage of chronic patients in households on the health payment-induced poverty with the control of other covariates.

Results: In rural areas, the incidence of poverty increased $31.90 \%$ before and after health payment in the household group when the percentage of chronic patients in the households was 0, and the poverty gap rose from 932.77 CNY to 1253.85 CNY (50.56\% increased). In the group when the percentage of chronic patients in the households was 1$40 \%$ and $41-50 \%$, the poverty gap increased 76.78 and $89.29 \%$, respectively. In the group when the percentage of chronic patients in the households was 51 100\%, the increase of poverty headcount and poverty gap was 49.89 and 46.24\%. In the logistic model, we found that the proportion of chronic patients in the households was closely related with the health payment-induced poverty. The percentage of chronic disease in the households increased by $1 \%$, the incidence of poverty increased by 1.01 times. On the other hand, the male household head and the household's head with higher educational lever were seen as protective factors for impoverishment.

Conclusions: With the percentage of chronic patients in the households growing, the health payment-induced poverty increases sharply. Furthermore, the households members with more chronic diseases in rural areas were more likely to suffer poverty than those in urban areas. Our analysis emphasizes the need to protect households from the impoverishment of chronic diseases, and our findings will provide suggestions for further healthcare reforms in China and guidance for vulnerable groups.
\end{abstract}

Keywords: China, Chronic diseases, Health payment-induced poverty, Logistic model, NHSS

\footnotetext{
* Correspondence: zzliang1981@mail.xjtu.edu.cn

${ }^{2}$ School of Public Policy and Administration, Xi'an Jiaotong University, No. 28

Xianning West Road, Xi'an 710049, Shaanxi, China

Full list of author information is available at the end of the article
}

(c) The Author(s). 2018 Open Access This article is distributed under the terms of the Creative Commons Attribution 4.0 International License (http://creativecommons.org/licenses/by/4.0/), which permits unrestricted use, distribution, and reproduction in any medium, provided you give appropriate credit to the original author(s) and the source, provide a link to the Creative Commons license, and indicate if changes were made. The Creative Commons Public Domain Dedication waiver (http://creativecommons.org/publicdomain/zero/1.0/) applies to the data made available in this article, unless otherwise stated. 


\section{Background}

China has been undergoing an epidemiological transition shifting from the infectious to the chronic diseases in the past three decades, which is much shorter than many other countries [1]. Chronic disease, defined as the diseases that affect people in a longer period in the future [2], mainly including cardiovascular diseases, diabetes, some cancers and so on [3], accounting for a majority of deaths and are responsible for a notable financial burden in low and middle-income countries, especially China $[4,5]$. The Fifth Chinese National Health Services Survey (NHSS) in 2013 showed that 400 million Chinese people were diagnosed with at least one chronic disease. The 2014 WHO Global Status report on NCDs showed that they are now the most important causes of mortality worldwide, and cause about 38 million lives lost in 2012. By 2013, 85\% of all deaths were due to chronic diseases, which caused about $70 \%$ of the total financial disease burden [6].

Chronic diseases impose heavy economic burdens on individuals, families and society. Family members with chronic diseases had a higher chance of experiencing health payment-induced poverty than those without, which is consistent in both developed countries and developing countries. In addition to the disease burden, chronic diseases may also impose a substantial economic cost [7]. Most low- and middleincome countries have relatively low levels of public expenditure on health care, inadequate health insurance, and relatively low coverage of health service. The shortfall in public expenditures on health care is usually made up by out-of-pocket (OOP) and other private health expenditures. So the effect of impoverishment caused by chronic diseases was rather heavily in the low- and middle-income countries [8]. According to a study conducted by Chunhong Jiang [9] showed that due to health expenses, an additional $10.53 \%$ of the families with a chronic patient got into poverty, which was more than twice the increase in the proportion of the families without a chronic patient.

The direct and indirect financial costs of chronic diseases to individuals and societies were enormous, while this trend still continues to grow. Direct costs include hospital costs, medical expenses, prevention costs, care-related travel, nursing, and family support costs. Indirect costs come from lower productivity, sick leave, loss of productive workers as a result of early retirement. These costs are heavy and can lead to poverty [10].

Many studies have shown that families with members who have chronic diseases face higher economic risks than other families, especially in developing countries, such as China $[11,12]$. In rural China, the situation is even worse, and the economic burden of chronic disease has risen to the point where out-of-pocket health payments cause many households to fall into poverty, and others who have already in poverty sink deeper [13].

This study aims to explore the impact of chronic diseases on the health payment-induced poverty in Shaanxi Province, China. The findings of this study will provide evidence on the health payment-induced poverty and relevant factors in households with chronic disease. Our findings may contribute to improving and adjusting related health policy, thereby further alleviating the economic burden of chronic disease.

\section{Methods \\ Data}

The data was obtained from the Fifth National Health Service Surveys (NHSS) of Shaanxi Province, which was conducted in 2013. NHSS was organized and directed by the National Health and Family Planning Commission of China every 5 years. Shaanxi province is located in the northwest of China, covering an areas of over 205,800 $\mathrm{Km}^{2}$. In 2013, it had a population of 37.6 million and $48.7 \%$ of residents lived in rural areas.

A four-stage, stratified, random sampling method was used in 2013 to ensure the representation of the whole population. In total, 32 counties (districts) were randomly selected in Shaanxi Province in the first stage, 160 towns were sampled in the second stage. In the third stage, 320 villages (communities) were selected in sampled townships. In total, 20,700 households were identified.

The study used a survey and qualitative methods to collect and analysis data. During the survey, all households members were interviewed individually using a structured household questionnaire. Data from the household survey was used to analysis the effect of the percentage of chronic disease in households on the health payment-induced poverty. Questions related to this paper included: demographic and socio-economic information on individuals and households, self-reported illness and injury, reported outpatient and inpatient health service utilization, questionnaire to measure annual household expenditure on food, accommodation, transportation, and out-of-pocket health expenditure and so on. The recall period for household expenditure questions was 1 year prior to the survey. An adult who was fully aware of the household income and expenditure information was eligible to respond in this section. Although the data were self-reported, the literature suggested that self-reported income tended to undertrue income in the survey [14]. So, following the literature, we used the household consumption expenditure to proxy economic status in this study.

Considering the fact that households living in rural areas are more likely to encounter poverty than households 
living in urban areas [3], we analysis the rural sample and urban sample separately.

\section{Health payment-induced poverty}

Health payment-induced poverty refers to the poverty absolutely attributable to health payment, which is measured by the difference between poverty before health payments are subtracted from total household income and poverty after they are subtracted. It occurs when health payments in a given year actually push a household below the poverty line (health payment-induced poverty), or further below the poverty line. Household may adopt many changes to cope with health paymentinduce poverty, which may influence household income and expenditure. The measurement of health paymentinduced poverty assumes that household expenditure is not responsive to the health payment and variation of expenditure is ignored.

We use three indices to capture the effect of chronic disease on poverty incidence, poverty depth and poverty intensity in households: poverty headcount ratio, poverty gap and mean positive poverty gap [15].

Poverty headcount is measured as the households who fall below the poverty line due to out-of-pocket health payment as a proportion of all the households in the population. Let $x_{i}$ be the per capita total expenditure of household $i$. An estimate of the gross of health payment poverty headcount is Eq. (1):

$$
H=\frac{\sum_{i=1}^{N} s_{i} p_{i}}{\sum_{i=1}^{N} s_{i}}
$$

Where $p_{i}=1$ if $x_{i}<\mathrm{PL}$ and is 0 otherwise, $s_{i}$ is the size of the household, and $N$ is the number of households in the sample.

Poverty gap (G) measures the percentage deficit from the poverty line of those households that have become poor due to out-of-pocket health payment. It is the "depth" of the poverty. The individual-level poverty gap is $g_{i}=p_{i}\left(P L-x_{i}\right)$, then the poverty gap of the whole sample could be defined as Eq. (2):

$$
G=\frac{\sum_{i=1}^{N} s_{i} g_{i}}{\sum_{\mathrm{i}=1}^{\mathrm{N}} s_{i}}
$$

The intensity of poverty is measured using the mean poverty gap (MPG), which represents the average deficit of the poor from the poverty line. Using Eq. (3):

$$
M P G=G / H
$$

To capture the effect of the percentage of chronic disease in the households on health payment-induce poverty, we firstly analysis the poverty measures before and after health payment in rural and urban areas respectively, then we analysis the influence of the percentage of chronic disease on the poverty before in rural and urban areas using logistic regression.

\section{Poverty line}

To compute poverty counts and gap, a poverty line needs to be established. Poverty line are either absolute or relative. An absolute poverty line defines poverty in relation to an absolute amount of household expenditure per capita. An extreme absolute poverty line indicates the cost of reaching subsistence nutritional requirements only. A relative poverty line is defined as some fraction of mean or median household expenditure. In this study, to make the results comparable internationally, we adopted the international poverty line, US\$ 1.25/day [16]. 2013 exchange rate: US $\$ 1=6.2$ Yuan.

\section{Quality control}

In order to ensure of the results of the survey to be accurate and reliable, the survey supervisors revisited 5\% of the sampled households to check the accuracy of data recorded by interviews. In this process, 14 key questions were asked again to check the consistency of the information recorded. The consistency rates of the key questions recorded between the first and second visits was over $95 \%$. The Mayer's Index of this sample is 1.63, indicating that there was a superior representation of the whole population [17].

\section{Ethical considerations}

This study was approved by the Ethics Committee of Xian Jiaotong University Health Science Center (approval number: 2015-644), and it conformed to the ethics guidelines of the Declaration of Helsinki.

\section{Statistical modeling}

We modeled associations between selected socioeconomic characteristics and the odds of becoming poor due to health payment using logistic regression. Demographic characteristics including four variables: having children in the household, household size, household head's gender, education of household head, household head's marriage. Having children in the household is a dummy variable indicating whether there were members in the household below 5 years old. Health insurance characteristics including two variables: social health insurance (divided into four groups) and commercial health insurance (i.e. whether the household member have commercial health insurance or not). The percentage of chronic disease in the household were divided into four groups (the first group is that the percentage of chronic disease in the households was 0 , the second group is $1 \sim 40$, the third group is $41 \sim 50$, the fourth group is $51 \sim 100)$. The utilization of health services 
including two variables: inpatient service usage (i.e. whether household members used inpatient services in the past 2 weeks) and outpatient usage (i.e. whether household members used inpatient services in the past year). The economic status of the household grouped into five quintiles. All of the analyses were performed using Stata 12.0. A two-sided $P<0.05$ was established as the level of statistical significance for all tests.

\section{Results}

\section{Characteristics of households}

Characteristics of all households enrolled in the study were shown in Table 1. In total, 21,700 households were evaluated. In rural areas, $74.91 \%$ of household heads were male, and $25.09 \%$ were female. While in urban areas, $65.31 \%$ of households were male, $34.69 \%$ were female. The proportion of households with child under 5 years old were $13.13 \%$ in rural areas and $15.87 \%$ in urban areas. The percentage of householders with a junior high school or higher degree were $81.31 \%$ in rural areas and $90.11 \%$ in urban areas. The proportion of households with all members covered by social health insurance were $81.31 \%$ in rural areas and $90.11 \%$ in urban areas. The percentage of chronic disease in households was divided into four parts. The proportion of households having at least 1 member with self-reported chronic diseases in urban areas (42.85\%) was significantly higher than that in rural areas (40.88\%). Detailed characteristics of households were in Table 1.

\section{Health payment-induced poverty in rural areas}

Table 2 shows the poverty measures before and after health payment in different groups in rural areas. We defined that the percentage of chronic patients in the households was $0 \%$ as group $1,1 \sim 40 \%$ as group 2, 41 $50 \%$ as group 3 and $51 \sim 100 \%$ as group 4 . Before health payment, $25.83 \%$ of households in group 1 were estimated to be in poverty, according to the international poverty line US $\$ 1.25 /$ day. After health payment, the poverty headcount increases to $34.07 \%$. A rise of $31.09 \%$ increase in poverty incidences. The estimated poverty gap rose $50.56 \%$, from 832.77 Yuan pre-health payment to 1253.85 Yuan post payment. The mean positive poverty gap also increase from 3223.68 Yuan to 3679.98 Yuan, representing a deepening of the poverty of the already poor.

In group 2, before and after health payment, a 50.56\% increase in the poverty headcount, a $76.78 \%$ increase in the poverty gap and a $14.78 \%$ increase in the mean poverty gap. In group 3, due to the health payment, a 56.68 and $89.29 \%$ increase of the poverty headcount and poverty gap, respectively. In group 4 , the increase in poverty headcount was $15.80 \%$, in poverty gap was $49.89 \%$.

\section{Health payment-induced poverty in urban areas}

Table 3 shows the poverty measures before and after health payment in different groups in urban areas. We can see the same trend in urban and rural areas. In group 1, before health payment, $12.55 \%$ households were estimated to be in poverty, after health payment, the poverty headcount rises to $16.87 \%$. In other three groups, despite the same trend when compared to rural areas, but we can see the households in urban areas suffer a bit lower impoverishment than rural areas. For all measures the difference in the estimate of poverty based on the household expenditure gross and net of health payments is statistically significantly different from zero at $5 \%$ or less.

\section{Factors associated with health payment-induced poverty headcount}

Table 4 provides the results obtained from the logistic regression models of health payment-induced poverty with other associated factors. As expected, most variables increased the risk of impoverishment. Interaction results show that, the percentage of chronic diseases in the households with health payment are 1.01 times to incur impoverishment in both rural areas and urban areas. With the member in the household increased, the chances of becoming impoverished increased. Inpatient health service usage increased the risk of suffering poverty 1.72 times in rural areas, and 1.62 times in urban areas. Compared to illiteracy, the household's head who have the higher education level were less likely to be impoverished due to health payment both in rural areas and urban areas. The low-income family in rural areas were 2.06 times suffering health payment-induced poverty, whereas there was no significant in urban areas. The male household's head was seen as the protective factor, the odds ratio (OR) was 0.55 (95\%CI: 0.47-0.65) in rural areas and $0.68(0.54-0.86)$ in urban areas. There was no statistically significant association between having children below 5 years old incurring poverty both in rural areas and urban areas.

\section{Discussion}

This study used the cross-sectional data from the 5th National Health Services Survey in Shaanxi Province to assess the effect of the percentage of chronic diseases in households on health payment-induced poverty. We measured the incidence, depth, and intensity of impoverishment health payment and provide strong evidence that medical expenditure is a financial burden for the households with chronic diseases members. We find that with the percentage of chronic diseases in the households growing, the health payment-induced poverty increases. Furthermore, rural households face more severe poverty problems than the urban areas residents. 
Table 1 Characteristics of households enrolled in this study (\%)

\begin{tabular}{|c|c|c|c|}
\hline Variables & Description & $\begin{array}{l}\text { Rural } \\
(n=13,200)\end{array}$ & $\begin{array}{l}\text { Urban } \\
(n=7500)\end{array}$ \\
\hline \multirow[t]{2}{*}{ Household head's gender } & $1^{\mathrm{a}}$ if the head of household was male & 74.91 & 65.31 \\
\hline & 2 if the head of household was female. & 25.09 & 34.69 \\
\hline \multirow[t]{3}{*}{ Household size } & $1^{a}$ if $1-2$ household members & 32.13 & 44.48 \\
\hline & 2 if 3-4 household members & 46.71 & 44.89 \\
\hline & 3 if more than 5 household members. & 21.16 & 10.63 \\
\hline \multirow[t]{2}{*}{ Having children in the household } & 1 if household having members below 5 years old & 13.13 & 15.87 \\
\hline & $0^{a}$ otherwise. & 86.87 & 84.13 \\
\hline \multirow[t]{5}{*}{ Household head's educational level } & $1^{a}$ if the head of household was illiteracy, & 18.69 & 9.89 \\
\hline & 2 if the head of household was elementary, & 31.58 & 17.21 \\
\hline & 3 if the head of household was middle school, & 35.81 & 32.52 \\
\hline & 4 if the head of household was high school, & 7.57 & 12.73 \\
\hline & 5 if the head of household was university. & 6.35 & 27.66 \\
\hline \multirow[t]{3}{*}{ Household head's marriage } & $1^{a}$ if the head of household was not married, & 5.46 & 2.83 \\
\hline & 2 if the head of household was married, & 72.02 & 74.84 \\
\hline & 3 if the head of household was else marriage & 22.52 & 22.33 \\
\hline \multirow[t]{2}{*}{ Outpatient service usage } & $\begin{array}{l}1^{a} \text { if household members used outpatient services in the } \\
\text { past two weeks, }\end{array}$ & 19.23 & 23.13 \\
\hline & $\begin{array}{l}2 \text { if no household members used outpatient services in the } \\
\text { past two weeks. }\end{array}$ & 80.77 & 76.87 \\
\hline \multirow[t]{2}{*}{ Inpatient service usage } & $1^{\mathrm{a}}$ if household members used inpatient services in the past year, & 9.11 & 10.50 \\
\hline & 2 if no household members used inpatient services in the past year, & 90.89 & 89.50 \\
\hline \multirow[t]{4}{*}{ Social health insurance } & $1^{a}$ if having household members covered by UEMS, & 1.04 & 25.38 \\
\hline & 2 if having household members covered by URMS, & 1.03 & 13.45 \\
\hline & 3 if having household members covered by NCMS. & 86.80 & 57.26 \\
\hline & 4 else. & 11.13 & 3.92 \\
\hline \multirow[t]{2}{*}{ Commercial health insurance } & $\begin{array}{l}1 \text { if having household members covered by commercial health } \\
\text { insurance, }\end{array}$ & 4.81 & 5.22 \\
\hline & $0^{a}$ otherwise. & 95.19 & 94.78 \\
\hline \multirow[t]{2}{*}{ Low-income family } & 1 if household was low-income family, & 17.28 & 9.61 \\
\hline & $0^{a}$ otherwise. & 82.72 & 90.39 \\
\hline \multirow[t]{4}{*}{ The percentage of chronic disease in the households } & $1^{\mathrm{a}}$ if the percentage of chronic disease in the households was 0 , & 59.12 & 57.15 \\
\hline & $\begin{array}{l}2 \text { if the percentage of chronic disease in the households was } \\
1 \sim 40,\end{array}$ & 16.36 & 17.33 \\
\hline & $\begin{array}{l}3 \text { if the percentage of chronic disease in the households was } \\
41 \sim 50 \text {, }\end{array}$ & 12.83 & 12.75 \\
\hline & $\begin{array}{l}4 \text { if the percentage of chronic disease in the households was } \\
51 \sim 100 .\end{array}$ & 11.70 & 12.77 \\
\hline \multirow[t]{5}{*}{ Economic status } & $1^{\mathrm{a}}$ if the $20 \%$ low income households, & 27.09 & 20.09 \\
\hline & 2 if the $20 \%$ low middle income households, & 21.14 & 19.91 \\
\hline & 3 if the $20 \%$ middle income households, & 18.05 & 21.33 \\
\hline & 4 if the $20 \%$ high middle income households, & 17.11 & 18.75 \\
\hline & 5 if the $20 \%$ high income households. & 16.61 & 19.92 \\
\hline \multirow[t]{3}{*}{ Region } & $1^{a}$ if household in Shannan, & 36.36 & 27.97 \\
\hline & 2 if household was in Guanzhong, & 45.45 & 56.03 \\
\hline & 3 if household in Shanbei. & 18.18 & 16.00 \\
\hline
\end{tabular}


Table 2 Measures of poverty gross and net of health payments in different groups in rural areas

\begin{tabular}{|c|c|c|c|c|}
\hline & \multirow{2}{*}{$\begin{array}{l}\text { Gross of } \\
\text { health } \\
\text { payment(1) }\end{array}$} & \multirow{2}{*}{$\begin{array}{l}\text { Net of } \\
\text { health } \\
\text { payment(2) }\end{array}$} & \multicolumn{2}{|l|}{ Difference } \\
\hline & & & Absolute(3) $=(2)-(1)$ & Relative $(4)=[(3) /(1)]^{\mathrm{a}} 100$ \\
\hline \multicolumn{5}{|l|}{ Group $1^{\mathrm{a}}$} \\
\hline Poverty headcount ${ }^{\mathrm{b}}$ & $25.83 \%$ & $34.07 \%$ & $8.24 \%$ & $31.90 \%$ \\
\hline Poverty gap(Yuan) & 832.77 & 1253.85 & 421.08 & $50.56 \%$ \\
\hline Mean positive poverty gap(Yuan) & 3223.68 & 3679.98 & 456.3 & $14.15 \%$ \\
\hline \multicolumn{5}{|l|}{ Group 2} \\
\hline Poverty headcount & $20.15 \%$ & $31.03 \%$ & $10.88 \%$ & $54.00 \%$ \\
\hline Poverty gap(Yuan) & 775.67 & 1371.24 & 595.57 & $76.78 \%$ \\
\hline Mean positive poverty gap(Yuan) & 3849.82 & 4418.68 & 568.86 & $14.78 \%$ \\
\hline \multicolumn{5}{|l|}{ Group 3} \\
\hline Poverty headcount & $28.35 \%$ & $44.42 \%$ & $16.07 \%$ & $56.68 \%$ \\
\hline Poverty gap(Yuan) & 907.40 & 1717.66 & 810.26 & $89.29 \%$ \\
\hline Mean positive poverty gap(Yuan) & 2865.07 & 3611.78 & 746.71 & $26.06 \%$ \\
\hline \multicolumn{5}{|l|}{ Group 4} \\
\hline Poverty headcount & $31.67 \%$ & $47.47 \%$ & $15.80 \%$ & $49.89 \%$ \\
\hline Poverty gap(Yuan) & 3851.58 & 5632.40 & 1780.82 & $46.24 \%$ \\
\hline Mean positive poverty gap(Yuan) & 6513.52 & 7785.52 & 1272 & $19.53 \%$ \\
\hline
\end{tabular}

${ }^{a}$ Group 1: percentage of chronic patients in the households was 0\%; Group 2: percentage of chronic patients in the households was 1 40\%; Group 3: percentage of chronic patients in the households was 41 50\%; Group 4: percentage of chronic patients in the households was 51 100\%

IInternational poverty line, US\$1.25/day. 2013 exchange rata: US\$1 $=6.2$ Yuan

Table 3 Measures of poverty gross and net of health payments in different groups in urban areas

\begin{tabular}{|c|c|c|c|c|}
\hline & \multirow{2}{*}{$\begin{array}{l}\text { Gross of } \\
\text { health payment(1) }\end{array}$} & \multirow{2}{*}{$\begin{array}{l}\text { Net of } \\
\text { health payment(2) }\end{array}$} & \multicolumn{2}{|l|}{ Difference } \\
\hline & & & Absolute(3) $=(2)-(1)$ & Relative $(4)=[(3) /(1)]^{*} 100$ \\
\hline \multicolumn{5}{|l|}{ Group 1* } \\
\hline Poverty headcount & $12.55 \%$ & $16.87 \%$ & $4.32 \%$ & $34.42 \%$ \\
\hline Poverty gap(Yuan) & 435.16 & 661.63 & 226.47 & $52.04 \%$ \\
\hline Mean positive poverty gap(Yuan) & 3466.71 & 3922.21 & 455.5 & $13.14 \%$ \\
\hline \multicolumn{5}{|l|}{ Group 2} \\
\hline Poverty headcount & $9.38 \%$ & $16.23 \%$ & $6.85 \%$ & $73.03 \%$ \\
\hline Poverty gap(Yuan) & 355.66 & 689.67 & 334.01 & $93.91 \%$ \\
\hline Mean positive poverty gap(Yuan) & 3789.79 & 4249.15 & 459.36 & $12.12 \%$ \\
\hline \multicolumn{5}{|l|}{ Group 3} \\
\hline Poverty headcount & $11.19 \%$ & $19.77 \%$ & $8.58 \%$ & $76.68 \%$ \\
\hline Poverty gap(Yuan) & 362.87 & 733.18 & 370.31 & $102.05 \%$ \\
\hline Mean positive poverty gap(Yuan) & 3242.07 & 3708.59 & 466.52 & $14.39 \%$ \\
\hline \multicolumn{5}{|l|}{ Group 4} \\
\hline Poverty headcount & $14.61 \%$ & $26.41 \%$ & $11.80 \%$ & $80.77 \%$ \\
\hline Poverty gap(Yuan) & 420.07 & 913.10 & 493.03 & $117.37 \%$ \\
\hline Mean positive poverty gap(Yuan) & 2874.47 & 3457.51 & 583.04 & $20.28 \%$ \\
\hline
\end{tabular}

*Group 1: percentage of chronic patients in the households was $0 \%$; Group 2: percentage of chronic patients in the households was 1 40\%; Group 3: percentage of chronic patients in the households was 41 50\%; Group 4: percentage of chronic patients in the households was 51 100\% 
Table 4 Determinants of poverty incidence in rural and urban areas of Shaanxi

\begin{tabular}{|c|c|c|}
\hline & \multicolumn{2}{|l|}{ Poverty incidence } \\
\hline & Rural areas OR(95\%Cl) & Urban areas $\mathrm{OR}(95 \% \mathrm{Cl})$ \\
\hline \multicolumn{3}{|l|}{ Health payment } \\
\hline Yes & $2.89(2.47-3.39) *$ & $2.20(1.71-2.83) *$ \\
\hline No & Ref & \\
\hline The percentage of chronic disease in the households & $0.99(0.99-1.00)$ & $0.99(0.99-1.00)$ \\
\hline $\begin{array}{l}\text { Health payment } \times \text { The percentage of chronic disease } \\
\text { in the households }\end{array}$ & $1.01(1.01-1.02) *$ & $1.01(1.00-1.01) *$ \\
\hline \multicolumn{3}{|l|}{ Household size } \\
\hline $1 \sim 2$ & ref & \\
\hline $3 \sim 4$ & $3.72(3.10-4.46) *$ & $1.65(1.21-2.25) *$ \\
\hline$\geq 5$ & $13.99(9.88-19.80) *$ & $4.19(2.31-7.62)^{*}$ \\
\hline \multicolumn{3}{|l|}{ Having children in the household } \\
\hline Yes & $1.28(0.20-7.78)$ & $1.05(0.68-1.63)$ \\
\hline No & Ref & \\
\hline \multicolumn{3}{|l|}{ Household head's gender } \\
\hline Female & Ref & \\
\hline Male & $0.55(0.47-0.65) *$ & $0.68(0.54-0.86) *$ \\
\hline \multicolumn{3}{|l|}{ Household head's educational level } \\
\hline Illiteracy & Ref & \\
\hline Elementary & $0.55(0.46-0.67) *$ & $0.83(0.62-1.01)$ \\
\hline Middle school & $0.40(0.33-0.49) *$ & $0.56(0.41-0.75) *$ \\
\hline High school & $0.39(0.28-0.52) *$ & $0.57(0.38-0.86) *$ \\
\hline University & $0.17(0.09-0.33) *$ & $0.26(0.13-0.53) *$ \\
\hline \multicolumn{3}{|l|}{ Household head's marriage } \\
\hline Unmarried & Ref & \\
\hline Married & $5.94(0.51-7.83)$ & $3.32(0.82-6.01)$ \\
\hline Else & $2.54(0.92-3.39)$ & $2.63(0.43-4.86)$ \\
\hline \multicolumn{3}{|l|}{ Outpatient service usage } \\
\hline Yes & $0.97(0.81-1.15)$ & $0.93(0.71-1.21)$ \\
\hline No & Ref & \\
\hline \multicolumn{3}{|l|}{ Inpatient service usage } \\
\hline Yes & $1.72(1.57-1.90) *$ & $1.62(1.45-1.86) *$ \\
\hline No & Ref & \\
\hline \multicolumn{3}{|l|}{ Low-income family } \\
\hline Yes & $2.06(1.58-2.69) *$ & $0.55(0.29-1.07)$ \\
\hline No & Ref & \\
\hline \multicolumn{3}{|l|}{ Region } \\
\hline Guanzhong & $1.36(1.17-1.58) *$ & $1.26(0.99-1.60)$ \\
\hline Shanbei & $1.16(0.97-1.40)$ & $0.55(0.39-0.41) *$ \\
\hline Shannan & Ref & \\
\hline
\end{tabular}

${ }^{* P} \leq 0.05$

Male household head and the household head with higher educational level were regarded as the significant protection factors from impoverishment, and the family in urban Shanbei was also less likely to experience poverty.
From the overall perspective of China, with the rapid economic growth, the poor population have been greatly reduced. But there still a population of 43.32 million was in severe poverty in China in 2016, impoverishment from 
medical expenses are still persistent. Chronic diseases not only have serious negative effects on quality of daily life of patients, but also bring huge losses of welfare to their family. In our study, more than $40 \%$ of the households had at least one member with chronic disease. Our results show that those households are at higher risk to fall into poverty than these without a member with chronic disease.

According to our findings, the male household head was seen as a protective factor, in rural areas 0.55 and in urban areas the OR was 0.68 , which is consistent with the former study [18]. We can explain this with the fact that male heads of households are always with a better conditions to provide the families with better economic status, such as the families main workforce, and the provider of the primary source of income of the family, so these households are expected to be healthy. Similar to the reports from other studies, household head's educational level was found to be another important protective factor of health payment-induced poverty. The reason for this result can be explained as the educational level of the household head is related to the communication attitudes towards health and health-related behaviors in the family. Therefore, the household head with higher education level can protect the families' health and reaction to health problems [19]. Unlike other studies $[20,21]$, our study found that the large household size was the risk factor of health payment-induced poverty. One of the potential reason is that the household with large size may have complicated family structure. The family with large size, maybe will have more patients or elders.

As expected, low-income households in rural areas are more likely to be poor due to health payment, while our research found that there was no statistically significant correlation with health payment-induced poverty in urban areas. This is mainly due to the limited ability of low-income households in rural areas to pay for non-living expenses, which is more likely to lead to poverty. In addition, low-income families are near the poverty line, which makes them more easier to fall into poverty or fall into deeper poverty, so in rural areas, many poor households will choose not to seek care when they get ill, rather than become impoverished [22]. Further efforts are needed to alleviate the financial burden of certain disadvantaged groups, such as the households with low-income.

In contrast to our expectation, we found that there was no significant association between impoverishment and households with a child or children, which was inconsistent with the study in Turkey [23]. Further studies are needed to explore the reason. Having inpatient patients in the household had a higher risk of incurring impoverishment.

Perhaps the main policy implication of our study is that policy makers need to understand whether there are any characteristics that make people more vulnerable to poverty caused by health payment, and should provide health insurance for the poor in order to reduce their vulnerability to health and financial shocks. Chronic diseases prevention is an important area for health policy development to reduce the economic burden of chronic diseases. Additionally, rural areas need a lot of investment because more than $70 \%$ of the poverty-stricken people live in the rural areas and they are the one who are more likely to fall into poverty.

Several limitations of our study should be acknowledged. Firstly, as the household income and consumer expenditures were both self-reported, recall bias might exist in the data, However, self-reported health service utilization and expenditure is widely used in the literature in the large-scale household survey. Secondly, the use of self-reported measures of chronic diseases may underestimate the prevalence of low- and middle-income households, particularly those with lower socioeconomic status. In addition, the chronic diseases were based on self-reported rather than being diagnosed by physicians, thus we could underestimate the disease burden. Thirdly, we used a higher poverty line than earlier studies, which use the poverty line of a dollar per day [5]. When compared with these studies, the poverty headcount, poverty gap and mean positive poverty gap may be overestimated. However, we centered around the relative differences of the poverty indexes before and after health payment, so the conclusion of our study would be reliable no matter which poverty line was used.

\section{Conclusions}

With the percentage of chronic patients in the households growing, the health payment-induced poverty increases. Furthermore, the households with more chronic disease in rural areas were more likely to suffer poverty than those in urban areas. Our analysis emphasizes on the need to protect households from the impoverishment of chronic diseases.

\section{Acknowledgements}

We would like to give our thanks to Shaanxi Health and Family Planning Commission for their data collection, we would also like to give our thanks to all the participants in this study for their participation and co-operation.

\section{Funding}

This study was funded by the National Natural Science Foundation (71874137), the Research Program of Shaanxi Soft Science (2015KRM117), Shaanxi provincial youth star of science and technology in 2016, the Basic Scientific Research Funding of Xi'an Jiaotong University (SK2015007), the National Program for Support of Top-notch Young Professionals and China Medical Board (15-227)

\section{Availability of data and materials}

The data used for this paper are from the 5th National Health Services Survey (NHSS) of Shaanxi Province. They are available from the Shaanxi Health and Family Planning Commission. Researchers who want to use these data may contact this institute upon request.

\section{Authors' contributions}

ZZ participated in the study conception and design, CS took part in the acquisition of data, $\mathrm{XL}$ analyzed the data, $\mathrm{YS}$ and $\mathrm{XF}$ interpreted the data, $\mathrm{XL}$ drafted and critically reviewed the manuscript for important intellectual content. XC and DT participated in the revision. All authors saw and approved the final version of the manuscript. 


\section{Ethics approval and consent to participate}

We obtained verbal informed consent from each participate and signed the informed consent before investigation. In order to get the cooperation from the sample counties, the Shaanxi Health and Family Planning Commission delivered a document, and guiders from the sample counties would contact each participant who agreed to accept the interview, and make an appointment with them. The investigators then went to the participants' house and collected information in our questionnaire, which means if we have participant's questionnaire, we have got the participants' consent. This method of consent in our study was approved by the Ethics Committee of Xi'an Jiaotong University Health Science Center (5th NHSS Approval No.2015-644), and it conformed to the ethics guidelines of the Declaration of Helsinki.

\section{Consent for publication}

Not applicable.

\section{Competing interests}

The authors declare that they have no competing interests.

\section{Publisher's Note}

Springer Nature remains neutral with regard to jurisdictional claims in published maps and institutional affiliations.

\section{Author details}

'School of Public Health, Xi'an Jiaotong University Health Science Center, No. 76 Yanta West Road, Xi'an 710061, Shaanxi, China. ${ }^{2}$ School of Public Policy and Administration, Xi'an Jiaotong University, No. 28 Xianning West Road, Xi'an 710049, Shaanxi, China. ${ }^{3}$ Center for Health Economics (CHE), Monash University, Melbourne, Australia. ${ }^{4}$ Department of Health Policy and Management and Department of Economics, Yale University, 60 College Street Suite 301, New Haven, CT 06510, USA.

Received: 8 February 2018 Accepted: 8 November 2018 Published online: 20 November 2018

\section{References}

1. Yang G, Kong L, Zhao W, Wan X, Zhai Y, Chen LC, Koplan JP. Health System Reform in China 3: Emergence of chronic non-communicable diseases in China. Lancet. 2008;372(9650):1697.

2. Daar AS, Singer PA, Persad DL, Pramming SK, Matthews DR, Beaglehole R, Bernstein A, Borysiewicz LK, Colagiuri S, Ganguly N, et al. Grand challenges in chronic non-communicable diseases. NATURE. 2007;450(7169):494-6.

3. Kien VD, Minh HV, Ngoc NB, Phuong TB, Ngan TT, Quam MB. Inequalities in household catastrophic health expenditure and impoverishment associated with noncommunicable diseases in chi Linh, Hai Duong, Vietnam. Asia Pac J Public Health. 2017;29(5_suppl):35S-44S.

4. Xu K, Evans DB, Kawabata K, Zeramdini R, Klavus J, Murray CJ. Household catastrophic health expenditure: a multicountry analysis. LANCET. 2003; 362(9378):111-7.

5. van Doorslaer E, O'Donnell O, Rannan-Eliya RP, Somanathan A, Adhikari SR, Garg CC, Harbianto D, Herrin AN, Huq MN, Ibragimova S, et al. Effect of payments for health care on poverty estimates in 11 countries in Asia: an analysis of household survey data. LANCET. 2006;368(9544):1357-64.

6. Wang Z, Li X, Chen M. Catastrophic health expenditures and its inequality in elderly households with chronic disease patients in China. Int J Equity Health. 2015;14(1):8.

7. Goryakin $Y$, Suhrcke M. The prevalence and determinants of catastrophic health expenditures attributable to non-communicable diseases in low- and middle-income countries: a methodological commentary. Int J Equity Health. 2014;13(1):107.

8. Lee JT, Hamid F, Pati S, Atun R, Millett C. Impact of noncommunicable disease multimorbidity on healthcare utilisation and out-of-pocket expenditures in middle-income countries: cross sectional analysis. PLoS One. 2015:10(7):e127199.

9. Jiang C, Ma J, Zhang X, Luo W. Measuring financial protection for health in families with chronic conditions in rural China. BMC Public Health. 2012;12:988.

10. Mathers CD, Lopez AD, Murray $C$. The burden of disease and mortality by condition: data, methods, and results for 2001; 2006.

11. Flores G, Krishnakumar J, O'Donnell O, van Doorslaer E. Coping with healthcare costs: implications for the measurement of catastrophic expenditures and poverty. Health Econ. 2008;17(12):1393-412.
12. Bhojani U, Thriveni B, Devadasan R, Munegowda C, Devadasan N, Kolsteren P, Criel B. Out-of-pocket healthcare payments on chronic conditions impoverish urban poor in Bangalore, India. BMC Public Health. 2012;12:990.

13. Liu Y, Rao K, Hsiao WC. Medical expenditure and rural impoverishment in China. J Health Popul Nutr. 2003;21(3):216-22.

14. Schultz TP. Designing household survey questionnaires for developing countries: lessons from fifteen years of the living standard measurement study. J Econ Lit. 2001;39(4):1232-4.

15. Van Doorslaer E, O'Donnell O, Wagstaf A. Analyzing Health Equity Using Household Survey Data: World Bank Publications; 2007. p. 301.

16. Ravallion M, Chen S, Sangraula P. Dollar a day revisited. World Bank Econ Rev. 2009;23(2):163-84.

17. Pardeshi GS. Age heaping and accuracy of age data collected during a community survey in the Yavatmal district, Maharashtra. Indian J Community Med. 2010;35(3):391-5.

18. Jing S, Yin A, Shi L, Liu J. Whether new cooperative Mmedical schemes reduce the economic burden of chronic disease in rural China. PLoS One. 2013;8(1):e53062.

19. Shi W, Chongsuvivatwong V, Geater A, Zhang H, Zhang J, Brombal D, Santonastaso M, Cortassa GM. Effect of household and village characteristics on financial catastrophe and impoverishment due to health care spending in Western and central rural China: a multilevel analysis. Health Res Policy Syst. 2011;9:21.

20. Patel V, Chisholm D, Kirkwood BR, Mabey D. Prioritizing health problems in women in developing countries: comparing the financial burden of reproductive tract infections, anaemia and depressive disorders in a community survey in India. Trop Med Int Health. 2006;12(1):130-9.

21. Sun J, Liabsuetrakul T, Fan Y, McNeil E. Protecting patients with cardiovascular diseases from catastrophic health expenditure and impoverishment by health finance reform. Tropical Med Int Health. 2015;20(12):1846-54.

22. Kawabata K, Xu K, Carrin G. Preventing impoverishment through protection against catastrophic health expenditure. Bull World Health Organ. 2002; 80(8):612.

23. Yardim MS, Cilingiroglu N, Yardim N. Catastrophic health expenditure and impoverishment in Turkey. Health Policy. 2010;94(1):26-33.
Ready to submit your research? Choose BMC and benefit from:
- fast, convenient online submission
- thorough peer review by experienced researchers in your field
- rapid publication on acceptance
- support for research data, including large and complex data types
- gold Open Access which fosters wider collaboration and increased citations
- maximum visibility for your research: over $100 \mathrm{M}$ website views per year
At BMC, research is always in progress.
Learn more biomedcentral.com/submissions 